\title{
Altered sleep patterns in patients with non-functional GHRH receptor
}

\author{
Francielle T Oliveira', Roberto Salvatori², José Marcondes³, Larissa B Macena', \\ Alecia A Oliveira-Santos', Augusto C N Faro', Viviane C Campos', \\ Carla R P Oliveira', Ursula M M Costa' ${ }^{1}$ and Manuel H Aguiar-Oliveira'
}

${ }^{1}$ Federal University of Sergipe, Division of Endocrinology, Aracaju, Brazil, ${ }^{2}$ Division of Endocrinology, Diabetes and Metabolism, The Johns Hopkins University School of Medicine (R.S.) Baltimore, Maryland, USA, and ${ }^{3}$ Institute of Sleep and Integrated Medicine, Aracaju, Brazil
Correspondence should be addressed to R Salvatori

Email

salvator@jhmi.edu

\begin{abstract}
Objectives: GH-releasing hormone (GHRH) exerts hypnotic actions increasing the non-rapid eye movement (NREM) sleep. Conversely, GH stimulates the REM sleep. GH deficiency (GHD) often leads to sleep problems, daytime fatigue and reduced quality of life (QoL). GHD may be due to lack of hypothalamic GHRH or destruction of somatotroph cells. We have described a cohort with isolated GHD (IGHD) due to GHRH resistance caused by a homozygous null mutation (c. $57+1 \mathrm{G}>\mathrm{A})$ in the GHRH receptor gene. They have normal QoL and no obvious complaints of chronic tiredness. The aim of this study was to determine the sleep quality in these subjects.

Methods: A cross-sectional study was carried out in 21 adult IGHD subjects, and 21 age- and gender-matched controls. Objective sleep assessment included polygraphic records of the awake, stages NREM [N1 (drowsiness), N2 and N3 (already sleeping)] and REM (R). Subjective evaluation included the Pittsburgh Sleep Quality Index, the Insomnia Severity Index and the Epworth Sleepiness Scale.

Results: IGHD subjects showed a reduction in sleep efficiency $(P=0.007)$, total sleep time $(P=0.028)$, duration of $\mathrm{N} 2$ and $\mathrm{R}$ in minutes $(P=0.026$ and $P=0.046$ respectively), but had increased duration and percentage of N1 stage $(P=0.029$ and $P=0.022$ respectively), wake $(P=0.007)$ and wake-time after sleep onset $(P=0.017)$. There was no difference in N3 or in sleep quality questionnaire scores.

Conclusion: Patients with IGHD due to GHRH resistance exhibit objective reduction in the sleep quality, with changes in NREM and REM sleep, with no detectable subjective consequences. GHRH resistance seems to have a preponderant role over GHD in the sleep quality of these subjects.
\end{abstract}

\section{Introduction}

Humans spend approximately one-third of their life sleeping (1). Human sleep is characterized by cyclic occurrence of periods of non-rapid eye movement (NREM) sleep, nearly three-quarters of the sleep, and the REM sleep $(2,3)$. Body size is important for environmental adaptation. Body size and sleep architecture are evolutionary regulated by reciprocal neuronal and humoral mechanisms (4). The relationship between sleep and stature is complex, and may include hormonal, metabolic and respiratory issues.
두 2017 European Society of Endocrinology Printed in Great Britain
Sleep problems coexists with short stature in several conditions such as hypothyroidism, achondroplasia, mucopolysaccharidoses, fragile X, Down's and PraderWilli syndromes (5). Down's syndrome subjects have low sleep efficiency, increased percentage of wakefulness after sleep onset (WASO), increase of the stage N1 (drowsiness) of NREM sleep and reduction of REM sleep (6). Patients with Prader-Willi syndrome have alteration in REM sleep, obstructive sleep apnea syndrome and severe 
daytime sleepiness $(7,8,9)$. Few studies in children with GH deficiency (GHD) suggest sleep fragmentation with decrease in total sleep time (TST), sleep efficiency and REM sleep and increase in N1 and WASO $(10,11)$.

Adult-onset GHD (AOGHD) individuals often complain of impaired quality of life (QoL) $(12,13,14)$ with frequent daytime fatigue associated to sleep problems, suggesting a relation between sleep and the somatotropic axis. Both GH and GH-releasing hormone (GHRH) secretion and action seem to be important in regulating sleep pattern $(15,16)$. Hypothalamic GHRH, together with interleukin $1 \mathrm{~B}$, tumor necrosis factor-alpha, and prostaglandin D, stimulates NREM sleep (17). GHRHergic neurons of the arcuate nucleus are involved in GH release from the pituitary, and the ones of the hypothalamus/ preoptic region (18) in NREM sleep regulation $(3,4,19)$. GHRH has hypnotic actions by increasing NREM sleep $(15,20,21)$, even in the absence of GH, which may stimulate the REM sleep $(22,23,24,25)$. Therefore, sleep disturbance may differ depending from the origin of GHD: in pituitary disease, there is potentially excessive compensatory hypothalamic GHRH activity, whereas in hypothalamic disorders GHRH activity is insufficient (12). Hypophysectomized rats after GHRH injection show an increase in NREM, but not in REM sleep (22). In mice with non-functional GHRH receptor (GHRHR) (little mouse) the duration of recovery after sleep deprivation is reduced (18). Similarly, inhibition of brain GHRH by GHRH antibodies inhibits spontaneous NREM sleep in rats (26, 27). In agreement with animal data, Copinschi et al. have shown that patients with GHD due to pituitary disease (with supposedly increased GHRH activity) spend more time in NREM sleep than their controls (12).

AOGHD individuals have often gonadal, adrenal and thyroid deficiency, which themselves (or their replacement therapy) may alter the quality of the sleep. In addition, some AOGHD patients have undergone brain surgery (and possibly receive anticonvulsants) or radiotherapy, all potentially able to influence the brain activities and sleep (28). Therefore, to assess the consequences of GHD on sleep, it would be ideal to have subjects with isolated GHD (IGHD). Few studies have investigated sleep quality in IGHD patients, and little is known about how sleep is altered in chronic GHRH deficiency $(10,29)$. In Northeastern Brazil, we have described a cohort of patients with IGHD due to GHRH resistance caused by a homozygous null mutation (c.57+1G $>$ A) in the GHRHR gene (GHRHR) (30). The adult IGHD individuals from this cohort who have not received GH replacement therapy have normal longevity (31) and QoL, and no obvious complaints of chronic tiredness (32). The aim of this study was to determine objectively and subjectively the sleep quality in these subjects.

\section{Subjects and methods}

\section{Subjects}

In a cross-ectional study, adult IGHD GH-naive subjects, and age and sex-matched controls were recruited by the local Dwarfs Association, among inhabitants of Itabaianinha by a posted add and by word of mouth. Inclusion criterion for IGHD was genotype-proven homozygosity for the $(c .57+1 \mathrm{G}>\mathrm{A})$ GHRHR mutation, whereas controls were normal statured individuals homozygous for the wild-type GHRHR allele. Exclusion criteria were: previous GH treatment, age under 18 and above 65 years, alcoholism or drug abuse, pregnancy, lactation, recent history (3 months) of serious illnesses or hospitalization, major psychiatric disorders, shift work, renal failure, chronic liver diseases, malignant neoplasms and current treatment with glucocorticoids, or medications that might affect their sleep. Twenty-one (10 males) IGHD and 21 (10 males) normal statured individuals volunteered and were enrolled. Individuals were transported by car in groups of three to Aracaju (approximately $150 \mathrm{~km}$ from Itabaianinha) in the afternoon, and were admitted to a specialized clinic at $1830 \mathrm{~h}$. They received a standard meal at $2000 \mathrm{~h}$, and were allowed to walk within the unit until $2300 \mathrm{~h}$, when lights were turned off, and the room was insulated from light. They were allowed to wake up spontaneously, and the exam was considered sufficient when there was a record of at least $6 \mathrm{~h}$ of sleep. The local sunrise during the realization of the protocol was at $0600 \mathrm{~h}$. The Federal University of Sergipe Institutional Review Board approved these studies and all subjects gave written informed consent.

\section{Questionnaires for the assessment of sleep quality}

The Pittsburgh Sleep Quality Index (PSQI), the Insomnia Severity Index (ISI), and the Epworth Sleepiness Scale (ESS) were translated into Portuguese. They were administered before the sleep studies and filled by the same investigator (F T O), as some individuals in both groups were illiterate. PSQI is an adult validated 19-item instrument grouped in seven components: subjective sleep quality, sleep latency, sleep duration, habitual sleep efficiency, sleep disturbances, use of sleeping medications and daytime dysfunction over the last month. Each component has a 
range of zero to 3 , and the sum of all the fields provides a global PSQI ranging from 0 to 21 , with the highest score indicating poorer sleep quality. A global PSQI greater than 5 has $89.6 \%$ sensitivity and $86.5 \%$ specificity to identify patients with poor sleep quality versus those with good quality (33). ISI assesses the severity of insomnia perceived in the previous 2 weeks, consisting of seven items, each ranging from 0 (no symptoms) to 4 (severe symptoms). Total score categories were thus coded, 0 to 7 , no clinical significant insomnia; 8 to 14 , sub-threshold insomnia; 15 to 21 , moderate insomnia; 22 to 28 , severe insomnia (34). The Epworth Sleepiness Scale (ESS) is a self-reported score that measures daytime sleepiness as well as the likelihood of falling asleep in eight situations, scored from 0 (the least sleepy) to 24 (the most sleepy). Scores equal to or above 10 are consistent with excessive daytime sleepiness (35).

\section{Polysomnography (PSG)}

Nocturnal, laboratory based polysomnography (PSG) was carried out under standardized conditions (FastPoly 26i 26-Channel Digital Polygraph, São Paulo, Brazil). This included electroencephalography (EEG) to monitor sleep stage, electrooculography (EOG) to monitor eye movements, electrocardiography (ECG), surface submental electromyography (EMG) to record atonia during REM sleep, measurement of chest wall and abdominal breathing movements, and transcutaneous oxygen saturation (36). Sleep was divided into periods of $30 \mathrm{~s}$, and the sleep stages were scored according to the American Academy of Sleep Medicine Manual for the Scoring of Sleep and Associated Events (AASM) (37), in wake (W), NREM: N1, drowsiness; N2, characterized by theta EEG frequency, being the largest percentage of total sleep; N3, slow wave sleep; and REM (R), characterized by rapid eye movements and atonia (1). The following variables were analyzed:

- Total recording time (TRT), in minutes: time from lights-out to light- on.

- Sleep latency (SL), in minutes: time from lights-out to first epoch of any sleep.

- Total sleep time (TST), in minutes: the sum of sleep stages (N1, N2, N3, R).

- Sleep efficiency (SE): the percentage of the TST in relation the TRT.

- REM latency, in minutes: time from the start of the first epoch of any sleep until the start of the first epoch of stage $\mathrm{R}$.
- Wake (W), in minutes: all the wake minutes during TRT.

- Wake after the sleep onset (WASO), in minutes: all the stage $\mathrm{W}$ from the start of the first epoch of sleep until lights-on.

- Time in each sleep stage (N1, N2, N3 and R) in minutes and percentage of TST.

- Arousal index: total number of arousals $\times 60 /$ TST in minutes.

Abnormal breathing events during sleep as apnea or hypopnea were recorded and the total number of events per hour was the apnea-hypopnea index (AHI). AHI higher than 5 per hour defines obstructive sleep apnea syndrome (OSAS). The number of times per hour of sleep in which the oxygen saturation decreases of or greater than $3 \%$ corresponds to the oxygen desaturation index (ODI) $(2,38)$.

\section{Ethical approval}

All procedures performed in studies involving human participants were in accordance with the ethical standards of the institutional and national research committee and with the 1964 Helsinki declaration and its later amendments or comparable ethical standards.

\section{Statistical analysis}

Data are expressed as mean (standard deviation), except for sleep latency, TST, sleep efficiency, wake, WASO, N1/TST (\%), N2/TST (\%), N2 in minutes, R/TST (\%), oxygen desaturation index (ODI) expressed as median (interquartile range). Student's $t$-test was used for variables with normal distribution, and Mann-Whitney $U$ test for variables without Gaussian distribution. We performed a median split division of the whole group in younger (21 individuals under the age of 41 years) and older (21 individuals equal or above the age of 41 years). A further analysis by gender ( 22 women and 20 men) was also fulfilled. Statistical analysis was performed using the statistical software SPSS 19.0 version. $P$ values under 0.05 were considered significant.

\section{Results}

Table 1 provides the demographic and subjective sleep questionnaires' quality data. The two groups have similar age and gender distribution. Only one subject in each group was older than 60 years. As expected, weight and 
Table 1 Anthropometric measures and scores of sleep quality assessed by the Pittsburgh Sleep Quality Assessment (PSQI), Insomnia Severity Index (ISI) and the Epworth Sleepiness Scale (ESS) in isolated GH deficiency (IGHD) subjects and controls. Data are presented as mean (S.D.).

\begin{tabular}{|c|c|c|c|}
\hline & $\begin{array}{l}\text { IGHD } \\
(n=21)\end{array}$ & $\begin{array}{c}\text { Controls } \\
(n=21)\end{array}$ & $\boldsymbol{P}$ \\
\hline Age (years) & $43.5(13.6)$ & $42.52(12.6)$ & 0.8 \\
\hline Sex (male) & 10 & 10 & 1.0 \\
\hline Weight (Kg) & $39.3(9.2)$ & $76.4(15.5)$ & $<0.0001$ \\
\hline Stature (meter) & $1.25(0.08)$ & $1.68(0.08)$ & $<0.0001$ \\
\hline Body mass index $\left(\mathrm{Kg} / \mathrm{m}^{2}\right)$ & $24.8(5.6)$ & $26.7(4.8)$ & 0.27 \\
\hline PSQI & $6.29(3.97)$ & $6.24(3.89)$ & 0.969 \\
\hline ISI & $6.86(5.22)$ & $7.86(5.49)$ & 0.549 \\
\hline ESS & 7.29 (3.54) & $8.95(5.16)$ & 0.230 \\
\hline
\end{tabular}

stature were lower in IGHD. Both IGHD and control subjects had a PSQI of greater than 5, without significant difference between the groups. Questionnaire data were not influenced by age and sex.

Table 2 shows the sleep parameters. In comparison to the control group, IGHD subjects exhibited reduced sleep efficiency $(P=0.007)$, total sleep time $(P=0.028)$ and duration of $\mathrm{N} 2$ and $\mathrm{R}$ in minutes $(P=0.026$ and $P=0.046$ respectively). The percentage of R/TST also tended to be lower $(P=0.087)$. Conversely, IGHD group had an increase in the duration of $\mathrm{N} 1$ stage and in the percentage of $\mathrm{N} 1 /$ TST ( $P=0.029$ and $P=0.022$ respectively). Wake was longer in IGHD $(P=0.007)$ probably due to the larger WASO $(P=0.017)$. There was no difference in percentage and minutes of stage N3 between two groups. The differences between IGHD and controls persisted only in the older group (41-65 years of age). In this age group, the duration of N3 was lower in IGHD than that in controls: 39 (26.9) vs 62.4 (23.5) min, $P=0.049$. Regarding gender, the reduction of sleep efficiency, total sleep time and duration of N2 were only maintained in males. The increase in N1 in minutes and N1/TST was found in both genders. The difference in N1/TST was maintained only in females, but the significance for N1 in minutes was lost in both genders when they were analyzed individually, although there was a tendency toward a N1/TST difference in men $(P=0.08)$. The reduction of $\mathrm{R}$ was similarly significant in both genders.

\section{Discussion}

Sleep is a rapidly reversible state of reduced responsiveness, motor activity and metabolism. Multiples theories exist
Table 2 Polysomnography parameters in 21 isolated GH deficiency (IGHD) subjects and 21 control subjects. Data are expressed as mean (S.D.), except for sleep latency, total sleep time (TST), sleep efficiency, stage wake, WASO, N1/TST (\%), N2/TST (\%), N2 (min), R/TST (\%), oxygen desaturation index (ODI) expressed as median (interquartile range).

\begin{tabular}{l}
\hline \\
\hline TRT (min) \\
Sleep latency (min) \\
TST (min) \\
Sleep efficiency (\%) \\
REM sleep latency \\
(min) \\
Stage wake (min) \\
WASO (min) \\
N1 (min) \\
N1/TST (\%) \\
N2 (min) \\
N2/TST (\%) \\
N3 (min) \\
N3/TST (\%) \\
R (min) \\
R/TST (\%) \\
Arousal index (/h) \\
ODI (events/h) \\
Apnea hypopnea \\
index (/h)
\end{tabular}

\begin{tabular}{c}
\hline IGHD \\
\hline $451.0(23.2)$ \\
$16.0(24.0)$ \\
$330.0(127.5)$ \\
$77.7(27.5)$ \\
$157.6(95.2)$ \\
\\
$96.5(123.5)$ \\
$82.5(116.5)$ \\
$51.3(33.7)$ \\
$14.6(18.9)$ \\
$190.0(81.7)$ \\
$57.7(15.6)$ \\
$51.1(36.5)$ \\
$15.5(9.5)$ \\
$45.6(27.3)$ \\
$11.9(8.1)$ \\
$12.2(9.8)$ \\
$3.5(8.9)$ \\
$10.2(10.7)$ \\
\end{tabular}

\begin{tabular}{clc}
\hline \multicolumn{1}{c}{ Controls } & & $\boldsymbol{P}$ \\
\cline { 1 - 1 } $442.9(31.4)$ & & 0.954 \\
$9.0(25.5)$ & & 0.623 \\
$385.5(56.0)$ & & 0.028 \\
$87.5(10.1)$ & & 0.007 \\
$118.5(44.5)$ & & 0.099 \\
& & \\
$54.3(51.7)$ & & 0.007 \\
$44.0(46.5)$ & & 0.017 \\
$31.8(19.8)$ & & 0.029 \\
$7.3(8.1)$ & & 0.022 \\
$220.0(43.2)$ & & 0.026 \\
$57.2(8.9)$ & & 0.296 \\
$61.9(20.8)$ & & 0.247 \\
$16.3(4.8)$ & & 0.718 \\
$61.5(22.8)$ & & 0.046 \\
$14.7(7.9)$ & & 0.087 \\
$14.7(10.3)$ & & 0.437 \\
$5.6(11.9)$ & & 0.296 \\
$13.0(12.4)$ & 0.446 \\
&
\end{tabular}

TRT, total recording time; TST, total sleeping time spent in stages N1, N2, N3 and R; Sleep efficiency, the percentage of the TST in relation to the TRT; WASO, wake after the sleep onset; arousal index, total number of arousals $x 60 /$ TST in minutes; ODI, number of events per hour of sleep in which the oxygen saturation decreases by or more than $3 \%$.

about its role, including restoration, energy conservation and memory consolidation (39). Within the last decade, GHRH has been put forward as a putative sleep-enhancing substance (40), extending NREM-time in rats and rabbits (41). Nevertheless, human studies are conflicting; some studies revealing significant increase in NREM after GHRH administration in healthy humans, whereas other studies have not confirmed this effect $(20,21,42)$.

We here report our findings of sleep quality in subjects with IGHD due to GHRH resistance. The main findings of this work are the reduction in sleep efficiency, total sleep time and total minutes of stages N2 and REM. Furthermore, IGHD group showed an extension of the drowsiness period (percentage and minutes of N1 stage) and of the wakefulness probably due to the larger WASO in adult individuals with a null homozygous (C.57+1G > A) GHRHR mutation. These data suggest a shorter and more fragmented sleep in these subjects. However, this seems not to have subjective consequences, as these changes were not reflected in differences in quality of sleep questionnaires. Other studies had shown an increased 
global PSQI in GHD, but these patients had associated multiple pituitary hormonal deficiency $(12,28)$ and confounders such as previous brain surgery, radiotherapy and hormonal replacement therapies may also play a role. The congenital nature of IGHD in our subjects may allow for adaptation mechanism(s) that may not be present in acquired GHD.

The reduction in sleep efficiency and total sleep time fits with data showing a NREM sleep-promoting activity of GHRH mediated by the hypothalamus/preoptic region. Rats and mice with deficiencies of GHRH signaling sleep less than normal animals (43). For example, little mice (also lacking a functional GHRHR) have less spontaneous NREM and REM sleep, do not respond to GHRH and chronic GH infusion restores REM but not NREM sleep (18). Accordingly, our patients have lower duration in minutes of the stages N2 of NREM and in REM sleep. Normal human subjects after sleep deprivation, the administration of GHRH reduces N1 stage and improves sleep efficiency (44). There is scant data, raised from very small number of patients with pituitary macroadenomas and hypothalamic involvement exhibiting shorter sleep duration, sleep fragmentation and disturbed circadian movement rhythms, possible via alteration of suprachiasmatic nucleus $(28,45)$. This hypothalamic nucleus is the major regulator of sleep-wake rhythmicity and is located close to the optic chiasm (28). Indeed, patients with hypothalamic GH deficiency secondary to brain tumors and thrombosis have lower intensity of NREM than that in normal controls (12). The increase of NREM after administration of GHRH seems independent of peripheral GH increase (44). GHD patients with primary pituitary lesions have lower $\mathrm{N} 1$ and duration (12), consistent with the hypothesis of an effect of GHRH on this parameter (46). Based on all these observations, we speculate that the lack of GHRH action in our model is more important than GHD in affecting sleep quality, suggesting that GH has lower influence in sleep quality than GHRH in humans, as recently proposed $(47,48)$.

Stage N1 is the typical transition from wakefulness to sleep. In senescence (after 60 years of age) (36) the percentage of N3 decreases (49) and the number of arousals increases with consequent increase in N1 (50). Most IGHD (and control) subjects were below this age threshold, and therefore IGHD and not age is responsible for this 'aging' sleep pattern. When we analyze the data by age group, we found that the differences between IGHD and controls persisted only in the older subgroup. In addition, in this subgroup we found a reduction in the duration of N3 in IGHD compared to controls, suggesting an additional effect of aging to GHRH receptor deficiency in this model. Interestingly, sleep, as skin ovary, and hearing seems to get older faster in IGHD than that in controls $(51,52)$, in contrast to bones, voice and blood vessels $(53,54,55)$.

When we compared the data by gender, most of the abnormal parameters of sleep found in the IGHD were only maintained in males, suggesting a more important role of GHRH in sleep in males. Previous studies that have shown a relevant sleep-promoting effect of GHRH were performed in healthy young men, and therefore could not provide gender comparison $(20,21,40)$.

Given the relative small number of subjects in each group after age and gender separation, more studies are needed to confirm a role of age and gender in sleep (25).

Differently from Laron syndrome (LS), a GH insensitivity condition with high circulating GH, we did not find a significant increase of obstructive sleep apnea syndrome (OSAS) in IGHD individuals. A narrow oropharynx secondary to a more severe obesity than the one of the IGHD subjects may predispose LS patients to OSAS (56). Interestingly, two LS patients showed a reduced percentage of REM during the IGF-1 therapy that seemed to occur simultaneously with decrease of GH levels. Since these patients are GH resistant, it is possible that the interactions between $\mathrm{GH}$ and REM sleep may be regulated by GH receptor-independent mechanisms (57).

Our study has some limitations. The major one is that-due to logistic limitations-we performed polysomnography only once, and a possible 'first night effect' cannot be ruled out. This however was the case for controls as well. Another limitation is that these patients, in addition to sharing the faulty GHRHR allele, may share other genetic traits that could influence the sleep. The recruitment of controls from the same geographical area reduces the risk of this possibility.

In conclusion, adult IGHD subjects lacking functional GHRHR exhibit objective reduction in sleep quality with changes in both NREM and REM sleep. The changes in NREM (longer duration of N1, and reduction of duration of N2), associated to increased WASO, seem more conspicuous than the mild reduction in the duration of REM sleep. These changes have minimal subjective consequences. Our data suggest a preponderant role of GHRH resistance over GHD in the sleep quality of these subjects. 
Declaration of interest

The authors declare that there is no conflict of interest that could be perceived as prejudicing the impartiality of this study.

\section{Funding}

This research did not receive any specific grant from any funding agency in the public, commercial or not-for-profit sector.

\section{Acknowledgments}

The authors thank the Associação do CrescimentoFísico e Humano de Itabaianinha, for their assistance.

\section{References}

1 Kirsch D. Stages and architeture of normal sleep. UpToDate, 2015.

2 Berry RB \& Gramaldo CE. The AASM Manual for the Scoring of Sleep and Associated Events: Rules, Terminology and Technical Specifications. Darien: American Academy of Sleep Medicine, 2014.

3 Steiger A. Sleep and endocrinology. Journal of Internal Medicine 2003 254 13-22. (doi:10.1046/j.1365-2796.2003.01175.x)

4 Krueger JM, Obal F Jr \& Fang J. Humoral regulation of physiological sleep: cytokines and GHRH. Journal of Sleep Research 19998 (Supplement 1) 53-59. (doi:10.1046/j.1365-2869.1999.00009.x)

5 Gadoth N \& Oksenberg A. Sleep and sleep disorders in rare hereditary diseases: a reminder for the pediatrician, pediatric and adult neurologist, general practitioner, and sleep specialist. Frontiers in Neurology 20145133.

6 Miano S, Bruni O, Elia M, Scifo L, Smerieri A, Trovato A, Verrillo E, Terzano MG \& Ferri R. Sleep phenotypes of intellectual disability: a polysomnographic evaluation in subjects with Down syndrome and Fragile-X syndrome. Clinical Neurophysiology 2008119 1242-1247. (doi:10.1016/j.clinph.2008.03.004)

7 Sedky K, Bennett DS \& Pumariega A. Prader Willi syndrome and obstructive sleep apnea: co-occurrence in the pediatric population. Journal of Clinical Sleep Medicine 201410 403-409.

8 Camfferman D, McEvoy RD, O'Donoghue F \& Lushington K. Prader Willi Syndrome and excessive daytime sleepiness. Sleep Medicine Review 200812 65-75. (doi:10.1016/j.smrv.2007.08.005)

9 Maas AP, Didden R, Bouts L, Smits MG \& Curfs LM. Scatter plot analysis of excessive daytime sleepiness and severe disruptive behavior in adults with Prader-Willi syndrome: a pilot study. Research in Developmental Disabilities 200930 529-537. (doi:10.1016/j. ridd.2008.08.001)

$10 \mathrm{Wu}$ RH \& Thorpy MJ. Effect of growth hormone treatment on sleep EEGs in growth hormone-deficient children. Sleep 198811 425-429. (doi:10.1093/sleep/11.5.425)

11 Verrillo E, Bizzarri C, Cappa M, Bruni O, Pavone M, Ferri R \& Cutrera R. Sleep characteristics in children with growth hormone deficiency. Neuroendocrinology 201194 66-74. (doi:10.1159/000326818)

12 Copinschi G, Nedeltcheva A, Leproult R, Morselli LL, Spiegel K, Martino E, Legros JJ, Weiss RE, Mockel J \& Van Cauter E. Sleep disturbances, daytime sleepiness, and quality of life in adults with growth hormone deficiency. Journal of Clinical Endocrinology and Metabolism 201095 2195-2202. (doi:10.1210/jc.2009-2080)

13 Cuneo RC, Salomon F, McGauley GA \& Sonksen PH. The growth hormone deficiency syndrome in adults. Clinical Endocrinology 1992 37 387-397. (doi:10.1111/j.1365-2265.1992.tb02347.x)

14 Blum WF, Shavrikova EP, Edwards DJ, Rosilio M, Hartman ML, Marin F, Valle D, van der Lely AJ, Attanasio AF, Strasburger CJ et al. Decreased quality of life in adult patients with growth hormone deficiency compared with general populations using the new, validated, self-weighted questionnaire, questions on life satisfaction hypopituitarism module. Journal of Clinical Endocrinology and Metabolism 200388 4158-4167. (doi:10.1210/jc.2002-021792)

15 Obal F Jr \& Krueger JM. GHRH and sleep. Sleep Medicine Review 2004 8 367-377. (doi:10.1016/j.smrv.2004.03.005)

16 Van Cauter E, Plat L \& Copinschi G. Interrelations between sleep and the somatotropic axis. Sleep 199821 553-566.

17 Krueger JM \& Obál F. Sleep regulatory substances. In Sleep science: Integrating basic research and clinical practice, pp 175-194: Karger Publishers, 1997.

18 Obal F Jr, Alt J, Taishi P, Gardi J \& Krueger JM. Sleep in mice with nonfunctional growth hormone-releasing hormone receptors. American Journal of Physiology: Regulatory, Integrative and Comparative Physiology 2003284 R131-R139. (doi:10.1152/ajpregu.00361.2002)

19 Zhang J, Obal F Jr, Zheng T, Fang J, Taishi P \& Krueger JM. Intrapreoptic microinjection of GHRH or its antagonist alters sleep in rats. Journal of Neuroscience 199919 2187-2194.

20 Steiger A, Guldner J, Hemmeter U, Rothe B, Wiedemann K \& Holsboer F. Effects of growth hormone-releasing hormone and somatostatin on sleep EEG and nocturnal hormone secretion in male controls. Neuroendocrinology 199256 566-573. (doi:10.1159/000126275)

21 Kerkhofs M, Van Cauter E, Van Onderbergen A, Caufriez A, Thorner MO \& Copinschi G. Sleep-promoting effects of growth hormonereleasing hormone in normal men. American Journal of Physiology 1993264 E594-E598.

22 Obal F Jr, Floyd R, Kapas L, Bodosi B \& Krueger JM. Effects of systemic GHRH on sleep in intact and hypophysectomized rats. American Journal of Physiology 1996270 E230-E237.

23 Mendelson WB, Slater S, Gold P \& Gillin JC. The effect of growth hormone administration on human sleep: a dose-response study. Biological Psychiatry 198015 613-618.

24 Astrom C. Interaction between sleep and growth hormone. Evaluated by manual polysomnography and automatic power spectrum analysis. Acta Neurologica Scandinavica 199592 281-296. (doi:10.1111/j.1600-0404.1995.tb00131.x)

25 Tanriverdi F, Karaca Z, Unluhizarci K \& Kelestimur F. Unusual effects of GH deficiency in adults: a review about the effects of GH on skin, sleep, and coagulation. Endocrine 201447 679-689. (doi:10.1007/ s12020-014-0276-0)

26 Obal F Jr, Payne L, Kapas L, Opp M \& Krueger JM. Inhibition of growth hormone-releasing factor suppresses both sleep and growth hormone secretion in the rat. Brain Research 1991557 149-153. (doi:10.1016/0006-8993(91)90128-I)

27 Obal F Jr, Payne L, Opp M, Alfoldi P, Kapas L \& Krueger JM. Growth hormone-releasing hormone antibodies suppress sleep and prevent enhancement of sleep after sleep deprivation. American Journal of Physiology 1992263 R1078-R1085.

28 Biermasz NR, Joustra SD, Donga E, Pereira AM, van Duinen N, van Dijk M, van der Klaauw AA, Corssmit EP, Lammers GJ, van Kralingen KW et al. Patients previously treated for nonfunctioning pituitary macroadenomas have disturbed sleep characteristics, circadian movement rhythm, and subjective sleep quality. Journal of Clinical Endocrinology and Metabolism 201196 1524-1532. (doi:10.1210/ jc.2010-2742)

29 Orr WC, Vogel GW, Stahl ML, Griffiths WJ \& Seely JR. Sleep patterns in growth hormone deficient children and age-matched controls: developmental considerations. Neuroendocrinology 197724 347-352. (doi:10.1159/000122721)

30 Salvatori R, Hayashida CY, Aguiar-Oliveira MH, Phillips JA III, Souza AH, Gondo RG, Toledo SP, Conceicao MM, Prince M, Maheshwari HG et al. Familial dwarfism due to a novel mutation of the growth hormone-releasing hormone receptor gene. Journal of Clinical Endocrinology and Metabolism 199984 917-923.

31 Aguiar-Oliveira MH, Oliveira FT, Pereira RM, Oliveira CR, Blackford A, Valenca EH, Santos EG, Gois-Junior MB, Meneguz-Moreno RA, 
Araujo VP et al. Longevity in untreated congenital growth hormone deficiency due to a homozygous mutation in the GHRH receptor gene. Journal of Clinical Endocrinology and Metabolism 201095 714-721. (doi:10.1210/jc.2009-1879)

32 Barbosa JA, Salvatori R, Oliveira CR, Pereira RM, Farias CT, Britto AV, Farias NT, Blackford A \& Aguiar-Oliveira MH. Quality of life in congenital, untreated, lifetime isolated growth hormone deficiency. Psychoneuroendocrinology 200934 894-900. (doi:10.1016/j. psyneuen.2009.01.001)

33 Buysse DJ, Reynolds CF III, Monk TH, Berman SR \& Kupfer DJ. The Pittsburgh Sleep Quality Index: a new instrument for psychiatric practice and research. Psychiatry Research 198928 193-213. (doi:10.1016/0165-1781(89)90047-4)

34 Bastien CH, Vallieres A \& Morin CM. Validation of the Insomnia Severity Index as an outcome measure for insomnia research. Sleep Medicine 20012 297-307. (doi:10.1016/S1389-9457(00)00065-4)

35 Johns MW. A new method for measuring daytime sleepiness: the Epworth sleepiness scale. Sleep 199114 540-545. (doi:10.1093/ sleep/14.6.540)

36 Moser D, Anderer P, Gruber G, Parapatics S, Loretz E, Boeck M, Kloesch G, Heller E, Schmidt A, Danker-Hopfe H et al. Sleep classification according to AASM and Rechtschaffen \& Kales: effects on sleep scoring parameters. Sleep 200932 139-149. (doi:10.1093/sleep/32.2.139)

37 Berry RB, Gamaldo CE, Harding SM, Brooks R, Lloyd RM, Vaughn BV \& Marcus CL. AASM Scoring Manual Version 2.2 Updates: New Chapters for Scoring Infant Sleep Staging and Home Sleep Apnea Testing. Journal of Clinical Sleep Medicine 201511 1253-1254. (doi:10.5664/jcsm.5176)

38 Rosenberg RS \& Van Hout S. The American Academy of Sleep Medicine Inter-scorer Reliability program: respiratory events. Journal of Clinical Sleep Medicine 201410 447-454.

39 Siegel JM. Sleep viewed as a state of adaptive inactivity. Nature Reviews Neuroscience 200910 747-753. (doi:10.1038/nrn2697)

40 Marshall L, Molle M, Boschen G, Steiger A, Fehm HL \& Born J. Greater efficacy of episodic than continuous growth hormonereleasing hormone (GHRH) administration in promoting slow-wave sleep (SWS). Journal of Clinical Endocrinology and Metabolism 199681 1009-1013.

41 Obal F Jr, Alfoldi P, Cady AB, Johannsen L, Sary G \& Krueger JM. Growth hormone-releasing factor enhances sleep in rats and rabbits. American Journal of Physiology 1988255 R310-R316.

42 Garry P, Roussel B, Cohen R, Biot-Laporte S, Charfi AE, Jouvet M \& Sassolas G. Diurnal administration of human growth hormonereleasing factor does not modify sleep and sleep-related growth hormone secretion in normal young men. Acta Endocrinologica 1985 110 158-163. (doi:10.1530/acta.0.1100158)

43 Obal F Jr \& Krueger JM. The somatotropic axis and sleep. Revue Neurologique 2001157 S12-S15.

44 Schussler P, Yassouridis A, Uhr M, Kluge M, Weikel J, Holsboer F \& Steiger A. Growth hormone-releasing hormone and corticotropinreleasing hormone enhance non-rapid-eye-movement sleep after sleep deprivation. American Journal of Physiology: Endocrinology and Metabolism 2006291 E549-E556. (doi:10.1152/ajpendo.00641.2005)

45 Borgers AJ, Romeijn N, van Someren E, Fliers E, Alkemade A $\&$ Bisschop PH. Compression of the optic chiasm is associated with permanent shorter sleep duration in patients with pituitary insufficiency. Clinical Endocrinology 201175 347-353. (doi:10.1111/ j.1365-2265.2011.04053.x)

46 Morselli LL, Nedeltcheva A, Leproult R, Spiegel K, Martino E, Legros JJ, Weiss RE, Mockel J, Van Cauter E \& Copinschi G. Impact of GH replacement therapy on sleep in adult patients with GH deficiency of pituitary origin. European Journal of Endocrinology 2013168 763-770. (doi:10.1530/EJE-12-1037)

47 Krueger JM \& Obal F Jr. Sleep function. Frontiers in Bioscience 20038 d511-519. (doi:10.2741/1031)

48 Liao F, Taishi P, Churchill L, Urza MJ \& Krueger JM. Localized suppression of cortical growth hormone-releasing hormone receptors state-specifically attenuates electroencephalographic delta waves. Journal of Neuroscience 201030 4151-4159. (doi:10.1523/ JNEUROSCI.6047-09.2010)

49 Ohayon MM, Carskadon MA, Guilleminault C \& Vitiello MV. Metaanalysis of quantitative sleep parameters from childhood to old age in healthy individuals: developing normative sleep values across the human lifespan. Sleep 200427 1255-1273.

50 Bonnet MH \& Arand DL. EEG arousal norms by age. Journal of Clinical Sleep Medicine 20073 271-274.

51 Menezes M, Salvatori R, Oliveira CR, Pereira RM, Souza AH, Nobrega LM, Cruz EA, Menezes M, Alves EO \& Aguiar-Oliveira $\mathrm{MH}$. Climacteric in untreated isolated growth hormone deficiency. Menopause 200815 743-747. (doi:10.1097/ gme.0b013e31815b97d4)

52 Prado-Barreto VM, Salvatori R, Santos Junior RC, BrandaoMartins MB, Correa EA, Garcez FB, Valenca EH, Souza AH, Pereira RM, Nunes MA et al. Hearing status in adult individuals with lifetime, untreated isolated growth hormone deficiency. Otolaryngology-Head and Neck Surgery 2014150 464-471. (doi:10.1177/0194599813517987)

53 Souza AH, Farias MI, Salvatori R, Silva GM, Santana JA, Pereira FA, de Paula FJ, Valenca EH, Melo EV, Barbosa RA et al. Lifetime, untreated isolated GH deficiency due to a GH-releasing hormone receptor mutation has beneficial consequences on bone status in older individuals, and does not influence their abdominal aorta calcification. Endocrine 201447 191-197.

54 Valenca EH, Souza AH, Oliveira AH, Valenca SL, Salvatori R, Goncalves MI, Oliveira-Neto LA, Barros AD, Nascimento UN, Oliveira CR et al. Voice quality in short stature with and without GH deficiency. Journal of Voice 201226 e613-e679.

55 Menezes Oliveira JL, Marques-Santos C, Barreto-Filho JA, Ximenes Filho R, de Oliveira Britto AV, Oliveira Souza AH, Prado CM, Pereira Oliveira CR, Pereira RM, Ribeiro Vicente Tde A et al. Lack of evidence of premature atherosclerosis in untreated severe isolated growth hormone (GH) deficiency due to a GH-releasing hormone receptor mutation. Journal of Clinical Endocrinology and Metabolism 200691 2093-2099. (doi:10.1210/jc.2005-2571)

56 Dagan Y, Abadi J, Lifschitz A \& Laron Z. Severe obstructive sleep apnoea syndrome in an adult patient with Laron syndrome. Growth Hormone \& IGF Research 200111 247-249. (doi:10.1054/ ghir.2001.0235)

57 Verrillo E, Bizzarri C, Cappa M, Bruni O, Pavone M \& Cutrera R. NREM sleep architecture and relation to GH/IGF-1 axis in Laron syndrome. Hormone Research in Paediatrics 201073 414-419. (doi:10.1159/000308177)

Received 17 February 2017

Revised version received 10 April 2017

Accepted 21 April 2017 